Revista lus et Praxis, Año 21, No 1, 2015, pp. 171 - 216

ISSN 0717 - 2877

Universidad de Talca - Facultad de Ciencias Jurídicas y Sociales

"El rol de la retribución en una teoría de la pena como institución regulativa"

Federico León Szczaranski Vargas

Trabajo recibido el 27 de mayo y aprobado el 12 de agosto de 2014

\title{
El rol de la retribución en una teoría de la pena como institución regulativa*
}

\author{
THE ROLE OF RETRIBUTION ON A THEORY \\ OF PUNISHMENT AS A REGULATIVE INSTITUTION
}

Federico LeÓn Szczaranski Vargas**

\begin{abstract}
RESUMEN
El artículo busca compatibilizar el reconocimiento de la culpabilidad como fundamento de la punición con la consecución de finalidades mediante la ejecución de la sanción penal. Así, en primer término se exponen objeciones a los intentos de armonización llevados a cabo por teorías eclécticas, para luego defender una concepción retribucionista de la pena, cuya compatibilización con la consecución de finalidades de restablecimiento normativo, se deja explicar adecuadamente en la medida que la práctica punitiva se comprenda como una institución "regulativa", cuya particular finalidad exige su operación como si se tratara de una institución "institutiva". Por último, se aborda el problema relativo a la inexistencia de una efectiva comunidad de intereses como presupuesto fundamental en la legitimación de un reproche penal, indicando a dicho respecto que la distancia entre la teoría emancipadora de una institución y su efectiva operación práctica, debe ser comprendida como la marca de un déficit de nuestras prácticas políticas.
\end{abstract}

ABSTRACT

The article seeks to reconcile the recognition of guilt as the foundation of punishment with the achievement of goals through the execution of the criminal sanction. So, in the first place, objections are put forward to the harmonization efforts undertaken by eclectic theories, then a retributive conception of punishment is defended, whose compatibility with the achievement of normative restoration is adequately explained to the extent that punitive practice should be understood as a "regulatory" institution, whose particular goal requires its operation as if it were a "institutive" institution. Finally, it is addressed the problem concerning the lack of a real community of interests, as fundamental presupposition in legitimizing criminal blame, indicating that the existing distance between the emancipatory theory of an institution and its effective practical operation, must be understood as the mark of a deficit in our political practices.

* Este trabajo forma parte del proyecto de investigación Fondecyt № 11121313 referido a Reiteración Delictiva, cuyo investigador responsable es el Dr. Francisco Maldonado Fuentes, a quien el autor agradece por sus valiosos comentarios. Igualmente agradece los comentarios de Guillermo Silva y de los evaluadores anónimos, los cuales permitieron mejorar el trabajo.

** Miembro del Centro de Estudios Penales y Penitenciarios, Universidad Mayor, Santiago, Chile. Magíster en Derecho Penal (Universidad de Talca, Chile y Universidad Pompeu Fabra, España). Correo electrónico: f.szczaranskiv@gmail.com. 
PalABRAS CLAVE

Teoría de la pena, Instituciones regulativas, Comunidad de intereses

KEYWORDS

Theory of punishment, Regulative institutions, Community of interests

\section{Introducción}

Protágoras, discutiendo con Sócrates sobre la posibilidad de enseñar la virtud, afirma la ya famosa frase según la cual "el que castiga con razón, castiga, no por las faltas pasadas, porque ya no es posible que lo que ya ha sucedido deje de suceder, sino por las faltas que puedan sobrevenir"; de forma tal que el castigo sólo es razonable si con él se evita la reincidencia y se ejemplifica al resto ${ }^{1}$. Ello es coherente con el entendimiento de la función de la ley que se ofrece: ellas tienen por objeto, justamente, enderezar mediante castigo a quien se ha separado ${ }^{2}$, es decir, producir efectos futuros positivos, consistentes en la evitación de nuevas desviaciones.

Pero, el punto que quiere hacer Protágoras no es directamente sobre la prevención. Antes bien, si quisiéramos llevar su discurso al día de hoy, Protágoras parece tener su foco puesto en la idea de culpabilidad, y por ello señala que a nadie se castiga por defectos naturales que no puede evitar: si no se tuviera capacidad para comportarse adecuadamente, argumenta, entonces el castigo no tendría sentido y en su lugar habría compasión. En cambio, los vicios y defectos que los hombres han adquirido pudiendo no haberlo hecho, y no porque les son inevitables (es decir, naturales), generan justamente reacciones de irritación. Ello puede fácilmente ser visto, a la luz actual, como un reconocimiento por parte de Protágoras a expresiones de reproche propias de las teorías retribucionistas y expresivas de la pena ${ }^{3}$.

De esta forma, el argumento completo de Platón es que esta "pena razonable", cuya finalidad es prevenir, presupone libertad para actuar; libertad que a su vez justifica reprochar el defecto que se busca prevenir. Así, ya en Protágoras encontramos un temprano intento por armonizar la prevención y culpabilidad, en que la primera supone la segunda.

A continuación se intentará defender que la mejor forma de realizar esta compatibilización entre ambas es mediante una concepción retributiva-restablecedora de la pena, que destaque y descanse en la naturaleza regulativa del derecho; la cual impide que la culpabilidad pueda servir como límite a necesidades preventivas de otra índole.

1 Platón (1871), pp. 35 y 36.

2 Platón (1871), pp. 39 y 40.

3 Feinberg (1974b), pp. 95 a 118. 


\section{Culpabilidad y prevención en la teoría de la unión}

La idea fundamental con la que ellas trabajan fue expuesta de forma elocuente a finales del siglo XIX por Adolf Merkel, para quien la contradicción entre los diversos fines que se asignan al derecho penal es sólo aparente, explicándose por una inadecuada relación entre delito y pena. Al respecto, hace ver que aun cuando la pena se funde en el delito cometido en el pasado, ello no impide mirar hacia el futuro en su aplicación, y da como ejemplo el que un deudor paga tanto porque ha contraído una deuda, como para satisfacer la pretensión del acreedor ${ }^{4}$. Así, al rechazar que la retribución de culpabilidad suponga excluir toda persecución de finalidades, es posible ver a la retribución misma como un medio para el logro de metas preventivas. Este intento de armonización se extendió mucho más allá de las fronteras del positivismo en que se originó, y se hace dominante en buena parte de los principales trabajos de la segunda mitad del siglo XX. Así, Jescheck sostiene que la pena se dicta sobre la base de su misión protectora de la sociedad, y que ello se logra compensando la culpabilidad, por cuanto "sólo la pena adecuada a la culpabilidad" disuade y educa, con lo que se alcanzan las finalidades preventivo-especiales resocializadoras, generales negativas ${ }^{5}$ y positivo-integradoras ${ }^{6}$. En una línea similar se encuentran los aportes de Stratenwerth, para quien todos los puntos de vista indicados destacan un aspecto esencial, pero parcial del problema ${ }^{7}$; Zipf, quien ve la conexión entre culpabilidad y prevención en la idea de responsabilidad del autor ${ }^{8}$; Maurach, cuyo trabajo asigna a la culpabilidad el rol de limitar la persecución de los fines preventivos dentro del marco del reproche ético social proporcional a la culpabilidad $^{9}$; y Frister, quien defendiendo los efectos preventivo-generales positivos de la pena, afirma que la opción de von Liszt debe imperar al momento de la determinación de la clase y configuración concreta de la pena ${ }^{10}$.

Ahora bien, así planteada, la crítica a las teorías eclécticas se puede sintetizar en la objeción de Jakobs: la unidad al interior de ellas tiene como costo la división del sujeto penado, ya que si se "reforma a un asesino para convertirlo en una persona pacífica -si es que ello es posible-, el trato con él -dicho de modo coloquial- no puede interpretarse de un solo trazo también como retri-

\footnotetext{
${ }^{4}$ Merkel (1910), p. 270.

5 JeSCHECK Y WeIGEND (2002), p. 81.

${ }^{6}$ JeSCHECK Y WeIGend (2002), p. 801.

7 Stratenwerth (2005), pp. 38-40;

${ }^{8}$ ZIPF (1982), pp. 354 y 358 especialmente.

${ }^{9}$ Maurach y Zipf (1994), pp. 109 y ss.

10 Frister (2009), pp. 66 y 71.
} 
bución de culpabilidad"; es decir, no se puede estar reprochando y reformando, al mismo tiempo, a la misma persona, ya que la "culpabilidad se retribuye a un responsable, mientras que se reforma al objeto de necesidades preventivas"11.

Por su parte, una opción como la de Schünemann, consistente en limitar el rol de la culpabilidad a una condición necesaria de la pena, y cuya relevancia se aprecia a la hora de su medición, pero que no obstante no habrá de ser retribuida por la imposición de la sanción ${ }^{12}$, tampoco puede considerarse satisfactoria. Se argumenta que la legitimidad de la pena descansa en la culpabilidad, ya que es en función de ésta que es posible afirmar que el autor del delito sabía o podía saber lo que le sucedería si delinquía, y que por ello, él recibirá como sanción lo que podía prever, autorizándose al Estado -con base en esa posibilidad de previsión- a hacer responsable al sujeto por su acción. Luego, aun cuando la culpabilidad no es el fundamento de la pena, ya que éste corresponde a criterios prevencionistas, la culpabilidad sí opera como condición necesaria, de forma tal que sin ella no es admisible la pena ${ }^{13}$. De la misma manera, son consideraciones prevencionistas las que determinan positivamente la magnitud de la pena, pero el juicio de culpabilidad sirve para ignorar aquellos antecedentes objetivamente relevantes a efectos preventivos, pero que no eran conocidos por el autor. Por ello, aun cuando la culpabilidad opera en el si, y en el cuanto de la pena; ella no es ni su fundamento, ni determina su magnitud ${ }^{14}$.

El problema con esta culpabilidad que no es reprochada es justamente el identificado por Schünemann: si el fin de la pena radica en proteger bienes jurídicos mediante prevención especial y general, entonces es extraño que tanto la imposición como la magnitud de la pena dependan de la culpabilidad, ya que lo normal es que el contenido de las consecuencias jurídicas de una institución se determine considerando su función, por lo que la noción de culpabilidad constituye un cuerpo extraño en este "moderno derecho penal preventivo"15. Ya que si de lo que se trata es de prevenir, ¿por qué el autor debe recibir sólo el mal que podía prever y no todo el necesario para prevenir? Y respecto de la magnitud, ¿por qué el hecho de que el autor no haya conocido ciertos factores relevantes para la prevención va a impedir que ellos sean considerados? Si la pena no retribuye, sino que sirve para prevenir, entonces ¿cómo se pueden explicar esas limitaciones? La respuesta se obtiene atendiendo a que, a pesar

\footnotetext{
11 JAKOBS (1998), p. 13.

12 Schünemann (1991), pp. 150 y 151.

13 SChünemann (1991), pp. 162 y 163

14 Schünemann (1991), p. 151 y 172-174.

15 Schünemann (1991), p. 152.
} 
de los intentos por excluir el reproche de la pena, la pena de Schünemann es explícitamente retributiva.

El autor explica que el delincuente sólo puede recibir el castigo que podía prever, ya que respecto de los demás, al no poder evitarlos, no es posible dirigirle "ningún reproche penal". Con la magnitud ocurre lo mismo: aun cuando un factor posea relevancia preventiva, si aquel no es conocido, entonces no corresponderá formular reproche alguno ${ }^{16}$.

Y es que, como nos recuerda Jakobs, la pena sólo puede limitar lo que se adecúa a su concepto ${ }^{17}$, y por ello, si la culpabilidad está limitando la reacción al delito, entonces la sanción no puede consistir en reeducación.

Lo mismo ocurre con la teoría de la unión de Roxin ${ }^{18}$. Al compaginar política criminal con dogmática, favoreciendo que las valoraciones de la primera penetren en el sistema de la segunda, y buscando con ello que la dogmática sea sensible a la "realidad social"19, Roxin complementa el principio de culpabilidad con consideraciones preventivo-generales referidas a las circunstancias personales o situacionales en las cuales no es indispensable la reacción penal ${ }^{20}$. En ese esquema, se sostiene que la pena sólo reconoce finalidades preventivas generales y -preponderantemente al momento de su ejecución- especiales ${ }^{21}$, pero que ellas, por cuanto carecen de barreras propias, requieren de la culpabilidad como límite externo. Luego -y como lo adelantamos con Schünemann-la pena no reprocha, ni su esencia es retributiva ${ }^{22}$, pero su aplicación se restringe, por motivos de garantía y justicia ${ }^{23}$, a hechos reprochables. De esta forma, se señala que en la conminación penal, el fin perseguido es de pura prevención general; luego, en la imposición de la pena, se consideran finalidades preventivo generales y especiales, pero limitado siempre por el principio de culpabilidad ${ }^{24}$; y finalmente, en la ejecución, pasa "totalmente a primer plano la prevención especial"25.

\footnotetext{
16 Schünemann (1991), pp. 163 y 173.

17 JаKовS (1998), p. 13.

${ }^{18}$ Mir lo sigue en ello: Mir (2003), pp. 90 y ss.

19 Roxin (2002), p. 52, concluyendo entonces que el derecho penal es la forma en la que las finalidades político-criminales se transforman en módulos de vigencia jurídica (p. 101).

${ }^{20}$ Roxin (2002), p. 59.

21 Roxin (1997), p. 97. Agregando que esa preferencia por la prevención especial llega hasta el punto en que la pena deje de ser considerada seriamente como una sanción.

22 Roxin (1997), p. 98.

${ }^{23}$ Ya que con la consideración de la culpabilidad no se estará utilizando al hombre como un medio (Roxin (1997), pp. 99 y ss.)

24 Roxin (1997), p. 99.

${ }^{25} \operatorname{Roxin}(1997)$, p. 97.
} 
Con Roxin ocurre la versión inversa del problema de su discípulo, Schünemann: mientras que el segundo fracasa en su teoría de la pena puramente prevencionista, puesto que para poder explicar las limitaciones a la pena fundadas en la culpabilidad debe conceder carácter retribucionista a ésta; el primero, al no contemplar la retribución como característica de la pena, se ve impedido de poder explicar cómo la culpabilidad podría limitar una pena no retributiva. Es decir, si la pena busca la resocialización, ¿cómo puede esa resocialización estar limitada por la culpabilidad? ¿Cuál es la relación entre ambas que permite que la segunda limite a la primera? Si la culpabilidad sólo puede limitar lo adecuado a su concepto, y a ello corresponde sólo la retribución, entonces sería necesario convertir la resocialización en retribución, limitar su magnitud en función de la culpabilidad, y una vez ya limitada, devolver esa magnitud de retribución a su forma de resocialización. Mientras no se ofrezca una forma de convertir resocialización en retribución, la vía de Roxin seguirá chocando con la objeción jakobsiana.

Peor aún, cuesta ver en qué consiste la función de garantía de la culpabilidad en el modelo de Roxin. Ello ya que el autor sostiene que la culpabilidad sirve de límite a la pena, por cuanto ésta -aun cuando no reprocha la culpabilidad- no es procedente a menos que la acción haya sido culpable. Pero al mismo tiempo entiende que las medidas de seguridad persiguen los mismos fines que la pena, pero de manera no limitada por la culpabilidad, y que ello se justifica en la lógica de protección de bienes jurídicos: se priva de libertad cuando el disfrute de la misma genera alta probabilidad de menoscabar bienes que pesan más que las restricciones que se imponen al causante del peligro ${ }^{26}$. Entonces, sólo se coaccionará sin culpabilidad en casos excepcionales de alta gravedad ${ }^{27}$, y en esos supuestos -Roxin explica- no se tratará de una pena, sino que de una medida de seguridad. Pero resulta que la diferencia entre pena y medida es meramente nominal, ya que ambas persiguen el mismo $\operatorname{fin}^{28}$ y ninguna reprocha. Sólo habría una diferencia si se admitiera que cuando se coacciona con culpabilidad, se está reprochando; y que cuando las necesidades obligan a que la coacción opere sin culpabilidad, ya no se puede reprochar. Pero si nunca hay reproche -ni en la pena ni en la medida-, y siempre se busca la prevención de delitos -tanto en la pena como en la medida-, entonces no puede distinguirse la pena de la medida de seguridad, y la garantía que presta la culpabilidad es mínima ${ }^{29}$.

\footnotetext{
${ }^{26}$ Roxin (1997), p. 105.

27 Roxin (1997), p. 107.

${ }^{28}$ Roxin (1997), pp. 104 y 105.

${ }^{29}$ Por lo anterior, si se sostiene que ni en la pena ni en la medida hay un juicio de reproche, pero que de todas formas hay una distinción entre ambas, entonces, no es posible afirmar que las dos persiguen
} 


\section{La exclusión del fin}

El punto de partida para la superación de la tensión entre culpabilidad y prevención se encuentra en el notable acierto de Mayer, quien, desde el neokantianismo, tempranamente advirtió que las finalidades perseguidas por el derecho no pueden ser inmediatamente consideradas al momento de su aplicación. Por el contrario, Mayer afirma que los fines perseguidos por el derecho deben quedar fuera de la institución por la cual se realizan, ya que se encuentra más allá de los límites conceptuales del medio para alcanzarlo ${ }^{30}$. Siendo ello así, la superación de la tensión indicada requiere, por una parte, aclarar cuál es la correcta finalidad que se persigue con la aplicación de la norma de sanción; y por otra, determinar en qué medida la finalidad de la sanción debe "penetrar" el proceso de su aplicación, teniendo en cuenta que, como se ha indicado, esos fines deberán estar -al menos en parte- fuera de la institución por la cual ellos se realizan.

Dieciséis años después de la muerte de Max Ernst Mayer, J. D. Mabbott publica el artículo "Punishment", con el cual se iniciará toda una corriente que buscará conciliar el reproche penal con el logro de finalidades futuras. La disuasión y reformación, sostiene Mabbott, podrían llevar a castigar a un inocente bajo ciertas condiciones. Por el contrario, lo único que puede justificar castigar a un hombre es su pasado, y ello importa que toda teoría de la pena que mire al futuro esté errada. El fundamento del castigo, por tanto, debe ser la retribución de un crimen ${ }^{31}$, excluyéndose cualquier consideración utilitarista al momento de determinar la aplicación de la pena. Pero ello no exige excluir el cálculo utilitarista en otras instancias, particularmente, en relación a la determinación acerca de qué leyes sería conveniente tener, y -más genérico aún- si acaso es

con su ejecución finalidades preventivo-especiales. Esa es, justamente, la opción de Jakobs: entendiendo que la culpabilidad designa las condiciones bajo las cuales es necesaria la pena para marginar el significado comunicativo del hecho -es decir, denomina "culpabilidad" a la suma de factores que determinan que la asimilación de esa conducta requiere de una reacción formalizada como lo es la pena (JAKOBS (2000b), p. 32)-, el autor afirma que ésta no tiene por finalidad alcanzar finalidades preventivas, ni tampoco -dada esa concepción de culpabilidad-manifestar un reproche material, sino que-como ya vimos-, restablecer la vigencia de la expectativa defraudada. Allí se ve la diferencia con las medidas de seguridad: ellas tampoco reprochan, pero a diferencia de la pena, la medida no busca restablecer expectativas, sino que persiguen -ahora si-finalidades preventivas especiales. Ello significa que la orientación normativa ha cedido a la cognitiva: no te trato suponiendo que te comportarás como deberías hacerlo conforme a derecho (es decir, como persona), sino que te trato suponiendo que te comportarás como yo entiendo que efectivamente te comportarás. Así, la reacción coactiva para prevenir un futuro uso incorrecto de la libertad define a la medida de seguridad (JAKOBS (2009), pp. 9 y 13). Sobre la aplicación conjunta de penas y medidas, véase: MALDONADO (2011), pp. 387 a 447.

30 MAYER (2007), p. 524.

31 МАввотт (1939), рр. 152 у 158. 
útil tener leyes, resultando así el castigo en un corolario no elegido por el legislador de la infracción de la norma ${ }^{32}$. De esta forma, señala Mabbott, son razones utilitaristas las que determinan la existencia de los mandatos y prohibiciones penales, pero una vez efectuada esa decisión, el cálculo utilitarista no puede desempeñar ningún rol en la aplicación de la sanción ante un incumplimiento, ya que si este tuviera lugar -es decir, si es que la aplicación supusiera volver a evaluar los antecedentes que sustentan la regla adoptada- entonces ya no podría decirse que hay una norma; y por ello, el juez no está en posición institucional de considerar aspectos preventivos o de resocialización al momento de definir y aplicar las sanciones ${ }^{33}$.

S. I. Benn luego profundiza en este modelo, afirmando que la distinción relevante es aquella que hay entre una regla, o una institución formada por reglas, por un lado; y una aplicación particular de las mismas, por otro. En esa medida, la justificación en general del castigo corresponde a la justificación de reglas que establecen el castigo de quienes las violan, y esa justificación es distinta de la justificación de una aplicación concreta de esas reglas. Ante ello, la fuerza del retribucionismo está en contestar la segunda pregunta; mientras que la fuerza del utilitarismo radica en contestar la primera: sólo se puede justificar reglas e instituciones apelando a sus beneficios ${ }^{34}$, y por ello regiría una condición formal respecto de la justificación del castigo, conforme a la cual las consecuencias de adoptar la institución deben ser preferibles a las de no adoptarla. Luego, si la principal ventaja de la adopción del castigo es la disminución del crimen -ya sea por reforma, prevención o intimidaciónesa ventaja debe sopesarse con el sufrimiento penal efectivamente infligido. Esas consideraciones utilitaristas que pueden justificar el castigo en términos generales, no pueden llevar en el caso concreto a castigar a un inocente, por cuanto el castigo mismo supone -como ya indicaba Mabbott- la no inocen$\mathrm{cia}^{35}$. Pero sobre todo, Benn afirma que el utilitarista no puede requerir que cada aplicación del castigo deba justificarse si es que con ella se causa más bien que mal: las reglas no serían reglas si ellas debieran ser aplicadas en cada caso sólo si su aplicación se justifica utilitariamente. Y ello sería aún

\footnotetext{
32 Маввотт (1939), р. 161.

${ }_{33}$ Маввотт (1939), pp. 157 y 164. El fundamento de esta idea, conforme a la cual el juicio de utilidad podría servir para validar instituciones que no son en su operación utilitaristas, podría encontrarse en MıLL (2009), p. 20: "I regard utility as the ultimate appeal on all ethical questions; but it must be utility in the largest sense, grounded on the permanent interests of man as a progressive being"; ello indicaría que no se debe considerar la utilidad en cada caso, sino que "todo considerado".

34 BENN (1958), p. 326.

35 BenN (1958), p. 330.
} 
más evidente en el caso de las reglas penales, ya que el castigo sirve como disuasión sólo si es aplicado regularmente ${ }^{36}$.

Con posterioridad, H.L.A. Hart defiende un esquema similar: no se puede confundir la retribución, como exigencia de castigar sólo a quien ha cometido un delito; con la idea de retribución como fin que justifica en general la pena. Este último radica en la obtención de consecuencias benéficas, pero la persecución de ese fin debe restringirse, por deferencia a principios distributivos, a afectar solo a los que han ofendido: la retribución cumple en Hart un rol negativo, conforme al cual no es posible perseguir los fines beneficiosos a costa de no culpables ${ }^{37}$.

Un razonamiento como el anterior lleva a Rawls a afirmar que legislador y juez operan mirando en direcciones opuestas: uno al pasado, el otro al futuro; la justificación del juez es retributiva, la del legislador es utilitaria. Pero, a diferencia de Hart, quien afirma que ante los diferentes momentos se deben abrazar principios contrapuestos, por lo que la persecución de los fines utilitariamente benéficos se ve, de hecho, limitada por consideraciones retribucionistas; la teoría de Rawls intenta negar que exista una oposición, por cuanto él entiende que la incidencia del retribucionismo en la aplicación de la pena a casos concretos se sigue de la asunción de un fundamento utilitarista de la práctica punitiva en general ${ }^{38}$. Así, una vez que se ha decidido, pensando en términos utilitaristas, recurrir al derecho penal, se ha decidido igualmente recurrir a una institución que razona retributivamente: el derecho penal es, para Rawls, una institución que conceptualmente se justifica en consideraciones retributivas ${ }^{39}$. Ello significa que son razones utilitaristas las que llevan adoptar una institución cuya práctica excluye las consideraciones utilitaristas. El juez, al igual que aquel que ha prometido algo, "no tiene derecho" a considerar argumentos utilitaristas, y es que habría ventajas utilitarias en una práctica que impide considerar argumentos utilitarios ${ }^{40}$.

36 BeNN (1958), p. 334.

${ }^{37}$ HART (2008), p. 9. A ello agrega que es esa finalidad de evitar la reiteración de conductas que consideran negativas, lo que permite distinguir la pena de un impuesto (p. 6).

${ }^{38}$ En esta línea, Gardner, en la Introducción al trabajo de Hart, hace presente que para este autor, y a diferencia de Rawls, la excepción a una regla retributiva en atención a consideraciones utilitaristas, constituye un costo cuya naturaleza es distinta a la pura pérdida marginal de utilidad (GARDNER (2008), pp. xix y ss.), lo que explica la observación de Hart, según la cual la negativa a que en un caso excepcional se ejecute a un negro inocente para evitar linchamientos públicos múltiples, sería inexplicable utilitariamente si con ello se está favoreciendo el beneficio total mediante el sacrificio de un principio que es visto sólo como un requerimiento de la utilidad misma (HART (2008), p. 12).

39 RAWLS (1955), p. 6.

40 RAWLS (1955), p. 16. 
La innovación de Rawls se encuentra en afirmar que esa distinción, entre la justificación de una práctica, y la de un caso particular, se explica mediante una concepción de las reglas como prácticas, las cuales lo que hacen es, valga la redundancia, definir una práctica, permitiendo la realización de una actividad que es imposible en ausencia de la regla, por lo que ésta es previa al caso particular. Así las cosas, participar en la práctica es seguir la regla, de forma tal que no se puede participar de ella y al mismo tiempo preguntar si acaso es conveniente seguir la regla ${ }^{41}$. Si se participa de una práctica, la razón para realizar una acción es que la regla que define la práctica así lo exige: esa regla es la que define la acción que se está realizando ${ }^{42}$. Y ese es el caso del juez ante la norma de sanción: en las reglas como prácticas, las razones utilitaristas que justifican a la regla no pueden ser consideradas al momento de su aplicación, ya que la consideración de esas razones es incompatible con la existencia de la práctica ${ }^{43}$. Así, no es posible jugar fútbol y al mismo tiempo cuestionar si es que acaso es conveniente que se cobre gol cuando la pelota traspasa la meta.

Es decir, el modelo extendido desde Mabbott a Rawls es coherente con lo que afirmaba Mayer: la razón o finalidad subyacente a la regla debe quedar fuera de juego a la hora de su aplicación. Pero, esa exclusión radical no es correcta. Esto es advertido tempranamente por Flew, quien -además de replicar a Mabbott que su propuesta no constituye una justificación retributiva del castigo, sino que una definición retributiva del castigo, por lo que sería impropio afirmar que el "castigo" de un inocente carece de justificación, ya que en ausencia de una infracción simplemente no hay castigo ${ }^{44}$ - formula el punto que acá es esencial: si el sistema punitivo se justifica por consideraciones utilitaristas, éstas sólo pueden excluirse de la operación de dicho sistema por regla general, pero nunca de manera definitiva; y por tanto, en algún caso extraordinario, la aplicación de la sanción requerirá traer de vuelta las finalidades que fundamentaron en un principio su adopción ${ }^{45}$.

\footnotetext{
${ }^{41}$ Si un futbolista preguntara si acaso pueden no cobrar el gol, ya que con ello el partido sería más interesante, se le explicaría que si no se cobra el gol cuando la pelota cruza la línea, entonces ya no se estará jugando fútbol. La regla del fútbol que especifica las condiciones bajo las cuales se ha convertido un gol no puede ser vista como un mero consejo al árbitro sobre lo que normalmente sería conveniente cobrar como gol (Rawls (1955), pp. 24 y ss.).

42 RAwls (1955), p. 27.

${ }^{43}$ Rawls (1955), p. 30.

${ }^{44}$ FLEW (1954), p. 300.

45 FLeW (1954), pp. 301 y 302.
} 


\subsection{La pena como institución regulativa}

La explicación de por qué la crítica de Flew es acertada, encuentra su origen en el trabajo de Searle, "The construction of social reality", luego continuado en "Making the social world", en que distingue entre reglas regulativas, que norman actividades preexistentes, y constitutivas, que se refieren a actividades que no existen sin esas reglas. Así, la regla que ordena manejar por la derecha es una regla "regulativa", ya que la actividad "manejar" es perfectamente posible sin necesidad de que exista una regla ${ }^{46}$.

En cambio, todas las instituciones humanas, argumenta Searle, descansan en reglas constitutivas. En la base de toda institución se encuentra un acto declarativo (aquellos que crean un estado de cosas mediante la declaración de dicho estado de cosas es el caso) que dispone que " $X$ cuenta como $Y$ en $C^{\prime \prime 47}$, de forma tal que el término $Y$ tiene que asignar un estatus (funcional) que no se posee previamente por la sola satisfacción de ser $X$, y que trae aparejado "poderes deónticos ${ }^{\prime \prime 4}$. En esta medida, en la base de las instituciones se encuentra en la cooperación humana (esto es, en la "imposición colectiva de función"), por cuanto se asignan a ciertos hechos funciones que no pueden ser cumplidas atendiendo sólo a propiedades físicas del mundo empírico: los hechos brutos pasan a indicar algo que va más allá de ellos ${ }^{49}$; y en esa medida, la declaración crea una realidad inexistente hasta antes de la regla.

Los deportes o juegos constituyen un caso paradigmático: la práctica de jugar fútbol es imposible en ausencia de reglas que establezcan qué es lo que cuenta como foul, gol, o tiro de esquina. Dicho de otra manera, no se puede anotar un gol si no existe previamente una regla que disponga que "Se habrá marcado un gol cuando el balón haya atravesado completamente la línea de meta entre los postes y por debajo del travesaño". En consideración a ello, Searle entiende que este tipo de reglas es constitutiva.

Ahora bien, Atria acierta al afirmar que de la existencia de reglas constitutivas, no se sigue necesariamente que la institución formada por ese conjunto de reglas sea una institución -a su vez- "constitutiva". Toda institución requiere de reglas constitutivas que asignen estatus funcionales con sus correspondientes

\footnotetext{
46 Searle (1995), p. 27.

47 Searle (2010), p. 13 y 99 y ss.: en ella se afirma que en términos generales toda creación de realidad institucional descansa en la declaración de que un estatus funcional $Y$ existe, es decir, son posibles instituciones en las que no exista un algo $(X)$ que cuente como $Y$, sino que derechamente se cree un estatus funcional "encima" de nada.

48 Searle (2010), p. 9.

49 Searle (2010), p. 85.
} 
poderes deónticos ${ }^{50}$, y en esa media, toda institución supone crear una actividad que no existía antes de las reglas que la definen. Pero para poder afirmar si una institución es regulativa o constitutiva, no basta con afirmar que se ha creado una nueva forma de comportamiento antes inexistente, es decir, no basta con afirmar la existencia de un hecho institucional. Se requiere preguntar por la razón por la cual dicho hecho institucional se ha creado. En las instituciones constitutivas, la razón de ser del hecho institucional creado se agota en sí mismo: la asignación de un estatus institucional a ciertos hechos brutos se explica sólo por cuanto con ello se busca crear la posibilidad de que ese hecho institucional exista, es decir, se considera que ciertos hechos brutos constituyen un "gol" con la sola finalidad de posibilitar que se conviertan goles, se crea el juego del fútbol sólo para poder jugar fútbol ${ }^{51}$. En esa medida, la actividad creada se justifica a sí misma.

Como vimos, en Rawls la pena es vista como una regla que opera de esta forma, ya que las reglas como prácticas son equivalentes a las reglas constitutivas: en ambos casos nos encontramos ante una regla cuyo seguimiento define una práctica inexistente si no es en atención a la regla. Por ello, para Rawls "participar en la práctica es seguir la regla", siendo contradictorio realizar la práctica y simultáneamente preguntarse si acaso es conveniente seguir la regla ${ }^{52}$.

Pero, en las instituciones "regulativas", si bien se crea un hecho institucional, es decir, un hecho inexistente hasta antes de las reglas que lo definen, su razón de ser no es crear una nueva actividad; sino que se crea esa nueva actividad por cuanto mediante ella se ve favorecida la consecución de efectos que se consideran deseables y que pueden conceptualizarse con independencia de las reglas constitutivas. Y justamente, uno de los casos más perspicuos de instituciones regulativas estaría dado por el Derecho. En el derecho, si bien se constituyen a ciertas circunstancias en "culpabilidad", a ciertas personas en "culpables" y a ciertos males en "pena"; esos hechos institucionales no se crean para permitir que existan "culpables", sino por cuanto ellos mismos facilitan el logro de determinados objetivos en principio independientes de las reglas, los que a su vez justifican a la institución ${ }^{53}$. De esta forma, las instituciones jurídicas existen para alcanzar ciertos efectos positivos en prácticas subyacentes a la institución ${ }^{54}$.

\footnotetext{
50 SeArle (2010), p. 167.

51 AtRIA (2001b), p. 26.

52 Rawls (1955), pp. 24 y ss.

53 ATRIA (2001b), p. 28: "[Law's] point is to regulate antecedently existing forms of behavior".

${ }^{54}$ Atria (2001b), pp. 24 y 25.
} 
Luego, si las instituciones regulativas se justifican en la medida que ellas permiten la consecución de ciertos objetivos, entonces esos objetivos no pueden ignorarse a la hora de la aplicación del derecho, por lo que aquel no podrá ser autónomo respecto de aquellos ${ }^{55}$. La consecuencia de esto es inevitable: mientras que en una institución constitutiva carece de sentido preguntarse si la aplicación que se hace de las reglas que la configuran sirve a la consecución de los fines que justifican a la institución, ya que el fin de la misma no es otro que el posibilitar la realización de una actividad que se define precisamente por el seguimiento de esas reglas, lo que significa que el seguimiento de las mismas es la satisfacción de la finalidad de la institución; en las instituciones regulativas tiene sentido cuestionar si acaso la aplicación de las reglas que la conforman sirve, efectivamente, a la consecución de sus fines, ya que ellos se identifican con la satisfacción de un objetivo que las reglas deberían favorecer, pero que son conceptualmente independiente de ellas.

Es decir, en tanto que una norma no puede regular su propia aplicación, por lo que la identificación correcta de su significado no basta para definir la forma en que la misma debe ser tratada, entonces factores como la finalidad de la norma pueden incidir en el grado de formalidad con la que ésta se aplica. Así, una misma regla, si forma parte de una institución regulativa debería aplicarse con un menor grado de formalidad que si ella perteneciera a una institución constitutiva. Ello ha llevado a proponer un entendimiento de las normas como esencialmente derrotables ${ }^{56}$, cualidad que no dependería de que el contenido de la norma incluya una cláusula que establezca como condición de aplicación la verificación de circunstancias normales, sino que se justificaría en que la misma sirva a la configuración de una institución regulativa. Así debe entenderse la propuesta de configurar las normas como integradas implícitamente por un defeater ${ }^{57}$ que dispone la imposición de la consecuencia normativa sólo en "casos normales" ${ }^{58}$ : el sentido de que dicho defeater esté implícito y no expreso en la estructura de la norma puede reconocerse como un intento por expresar la forma de operación de la norma mediante una referencia a su contenido, no obstante que la cualidad de derrotable de una norma no responde a este último, sino que es siempre una pregunta por la forma adecuada de tratar dicho contenido ${ }^{59}$.

\footnotetext{
55 ATRIA (2001b), pp. 30, 44 y 45.

56 Tur (2001), pp. 355 a 368; MacCormick (2005), Capítulo 12.

57 MORESO (2008), p. 48.

58 Atria (2004), pp. 131 y ss. Igualmente AtRIA (2001b), pp. 136 y 177.

59 SChauer (2012).
} 
La finalidad de todo esto -ya sea que se defienda la pertinencia de afirmar el defeater implícito en la estructura de la norma, o se sostenga simplemente que la derrotabilidad de la misma es una cualidad fundamental de su modo de aplicación- radica en favorecer una forma de razonamiento legal que sea formal, pero no formalista ${ }^{60}$ y evitar así que el seguimiento de las normas importe un compromiso con una teoría mecanicista de la adjudicación que sea ciega a las particularidades del caso, ordenando aplicar siempre la norma a todos los que caigan dentro de su tenor literal y sin dejar espacio alguno a la evaluación de si con ello se posibilitan los fines que justifican la institución.

Que esto sea así, explica la corrección de la observación de David Ross a una justificación utilitarista de la promesa, cuya similitud con el castigo permite extrapolarla: si la institución de la promesa se fundamenta en un juicio de utilidad, y nos encontramos ante un caso concreto en que, considerando todos los efectos, el incumplimiento de una promesa es más beneficioso que su respeto (incluyendo por cierto el daño que dicho incumplimiento implica para la subsistencia de la institución misma), entonces -en tanto institución regulativa-, en esos supuestos el incumplimiento debería permitirse ${ }^{61}$. Esto se explica justamente porque este tipo de institución no puede ser nunca completamente impermeable en su aplicación a los resultados que de ella se siguen para los objetivos que la justifican. Llevado esto al castigo, importa que si en un caso concreto la punición de un inocente reporta suficientemente más beneficios que costos, entonces la lógica de esta institución debe ordenar, para ese caso concreto, el castigo del inocente. Rawls cree poder responder a esto insistiendo en que el utilitarismo llevaría a que el juez no esté en posición de efectuar el cálculo utilitarista para decidir castigar, por lo que, aun si es que el castigo del inocente fuera lo más útil, el mismo utilitarismo le ha impedido al juez considerarlo ${ }^{62}$. Pero si las razones sustantivas subyacentes a la institución del castigo ordenan que nunca se puede castigar a un inocente, ni siquiera cuando, todo considerado -incluyendo el daño que ello ocasiona a la institución misma del castigo-, la punición sea más ventajosa; entonces la lógica con que operan esas razones sustantivas no es la lógica del utilitarismo ${ }^{63}$. Y es que el utilitarismo debería configurar la institución de la forma que ella produzca el mayor

\footnotetext{
${ }^{60}$ Sobre la distinción véase AтіYAн (1986), pp. 93 y ss.: se indica que tiene razón Raz al señalar que la norma no busca constituirse en una razón más para la acción, sino que por el contrario, busca reemplazar la demás razones; pero ese reemplazo tiene lugar dentro de ciertos límites cuyo reconocimiento evita el formalismo.

${ }^{61} \operatorname{Ross}(2002)$, p. 38.

62 RAWLS (1955), p. 16.

${ }_{63}$ Mañalich (2007), p. 130, siguiendo en esto la observación de Hart en HaRT (2008), p. 12.
} 
beneficio neto posible, y ello importa que la institución diseñada utilitariamente deberá castigar al inocente en el caso en que, todo considerado, aquello sea más beneficioso. Ello por lo demás sirve para explicar igualmente lo acertada de la crítica de Flew: si la adopción del sistema punitivo se justifica en que aquel permite alcanzar efectos preventivos positivos, entonces, por tratarse de una institución regulativa, en la operación del sistema esos efectos no pueden ser ignorados completamente, y en ciertos casos concretos se deberán considerar las razones utilitarias que fundamentan las practica.

Ese es justamente el caso con el modelo roxiniano. En éste, las finalidades preventivas que justifican al derecho penal permean la aplicación del mismo, pero lo hacen al costo de redefinir la culpabilidad en clave prevencionista, con lo que la pregunta por la culpabilidad del autor es dependiente de la afirmación de necesidades preventivas.

El problema de este modelo es que si bien permite dar cuenta de la naturaleza regulativa del derecho -por cuanto los efectos preventivos que para Roxin justifican el derecho penal son considerados en la ejecución de la pena-, la misma no tiene éxito en compatibilizar esas finalidades con el principio de culpabilidad. Ello por cuanto la penetración de las consideraciones político criminales en las estructuras dogmáticas lleva consigo que se complemente el principio de culpabilidad con consideraciones preventivo generales referidas a las circunstancias personales o situacionales en las cuales no es indispensable la reacción penal ${ }^{64}$. Ello significa que la necesidad de atribuir culpabilidad para poder aplicar la pena se satisface a sí misma: las finalidades preventivas contribuyen a determinar la culpabilidad, y, en esa medida, a excluir la inocencia. Es decir, se resuelve la tensión entre culpabilidad y prevención convirtiendo todo en prevención, ya que de haber suficientes necesidades preventivas, ya no se será inocente.

Esto ratifica las críticas de David Ross y Flew: la justificación teleológica del modelo roxiniano impide omitir la sanción si ella favorece la consecución de las finalidades definidas, por cuanto no será posible una limitación en razón de falta de culpabilidad, ya que si la satisfacción de las necesidades preventivas así lo requieren, la culpabilidad se verá afirmada. Es decir, si acaso en una situación concreta se reconoce la existencia de una hipótesis de inexigibilidad excluyente de la culpabilidad, ello dependerá de si en ese caso las consideraciones teleológicas relativas a la protección de bienes jurídicos exige o no la aplicación de una sanción ${ }^{65}$, con lo que la culpabilidad se revela como un límite sólo aparente.

${ }^{64}$ Roxin (2002), p. 59.

${ }^{65} \operatorname{Roxin}(2002)$, p. 60. 


\section{La armonización mediante retribución-restablecedora}

Lo anterior indica que la comprensión del derecho como institución regulativa, unida a una justificación del mismo en función de consideraciones preventivas del tipo indicado, termina por excluir a la culpabilidad del análisis relativo a la procedencia de la pena.

A continuación se intentará argumentar que una teoría de la pena retributiva, expresiva de reproche y referida al restablecimiento de la vigencia de la norma de conducta infringida, permite compatibilizar la afirmación original de Mayer-conforme a la cual el fin del derecho queda fuera del mismo-con el reconocimiento de la naturaleza regulativa del derecho penal que exige en su aplicación la consideración de las finalidades que lo justifican. Solo en esa medida, se puede armonizar la culpabilidad del autor con satisfacción de las finalidades del derecho penal.

\subsection{La exclusividad del reproche}

Ya Protágoras adelantaba que el castigo de un comportamiento defectuoso expresa una reacción de irritación ante el pecado. Y esa cualidad expresiva no es vista por el retribucionismo sólo como un elemento accidental o secundario del castigo, sino que constituye su elemento definitorio.

Para adentrarse en esta dimensión, puede valer la pena comenzar refiriéndose al trabajo de Joel Feinberg. Aun cuando su teoría no debería ser considerada retribucionista ${ }^{66}$, la dimensión expresivo-reprobatoria del castigo que Feinberg destaca, resulta esencial para la caracterización de la pena en las teorías retribucionistas contemporáneas. Así, Feinberg critica las definiciones de castigo ofrecidas por Hart, Flew y Benn, por cuanto ninguna de ellas da cuenta, justamente, de esta cualidad expresiva, indicando que a diferencia de una "penalty", como podría ser una multa de tránsito, la pena constituye un castigo por cuanto ella constituye un vehículo convencional para la expresión de actitudes de indignación, resentimiento, juicios de reprobación y reproche; lo que le da pie para distinguir entre el maltrato mismo en que la pena consiste y el significado simbólico de reprobación que ese maltrato expresa, concluyendo

\footnotetext{
${ }^{66}$ Así, Feinberg critica las corrientes típicamente retribucionistas que comprenden al merecimiento como un factor independiente que debe ser ponderado por sí solo en relación a otras consideraciones de carácter teleológico, indicando que el abandono de ese errado entendimiento serviría para terminar la disputa entre retribucionismo y utilitarismo (FeINBERG (1974a), p. 69). Igualmente, respecto de las diferencias que pueden afirmarse entre una teoría expresiva de la pena y el retribucionismo, Mañalich hace presente que "Una concepción de la pena como acto expresivo no supone asumir como correcta la dialéctica de la negación que subyace a la justificación idealista de la pena como negación de la negación del derecho (que es el sentido que tiene el delito)" (2005), p. 70.
} 
entonces que lo característico de la pena es que ella expresa un sentimiento de condena, reproche o reprobación por parte de la comunidad ${ }^{67}$. En términos similares, Morris justifica la pena como un castigo que anula ventajas injustamente obtenidas y que reconoce al delincuente el derecho de ser tratado como persona $^{68}$, entendiendo que la determinación de que alguien es culpable, y el posterior castigo que ello origina, enseña y refuerza valores sociales relevantes, comunicando que la norma infringida existe y que debe ser tomada en serio ${ }^{69}$. También desde el realismo jurídico se afirman cualidades de este tipo respecto de la pena; así, Alf Ross sostiene que la sanción cumple la función pragmática de expresar el sentimiento de desaprobación como censura o reproche, siendo necesaria esa manifestación para poder distinguir el maltrato inherente a un tratamiento terapéutico de aquel maltrato propio de una pena ${ }^{70}$.

Esta dimensión expresiva es constitutiva de la teoría retributiva de Kindhäuser, la que ha sido notablemente defendida en Chile por Mañalich. En este caso se defiende una concepción retribucionista de la pena que descansa en la comprensión del derecho como el resultado de un proceso de entendimiento que coordina intereses mediante lenguaje, coordinación que a su vez supone - por parte de los partícipes de la comunicación- reconocimiento recíproco de autonomía comunicativa individual, consistente esta última en la atribución mutua de capacidad y autorización para participar en dicho proceso de entendimiento $^{71}$. Dados estos presupuestos, se legitima una expectativa de fidelidad al derecho respecto de cada uno de los miembros de la comunidad. De esta forma, la legitimidad del reproche depende de la posibilidad de reconducir democráticamente la norma de conducta vulnerada al mismo infractor, por cuanto él, en tanto miembro de la comunidad política, ha podido tomar parte en la generación de aquella. Es decir, si la creación de la norma se reconduce a la libertad comunicativa de cada uno de los agentes, entonces, como contrapartida de esa libertad se encuentra un deber de lealtad comunicativa según el cual un desacuerdo del sujeto con la norma sólo puede expresarse institucionalmente ${ }^{72}$. Luego, la falta de motivación para seguir la norma así producida constituye un déficit de lealtad comunicativa con los demás miembros de la comunidad, es

67 De la comunidad, o más genéricamente, de quien está castigando o de aquel en cuyo nombre se está castigando (FEINBERG (1974b), pp. 98 y 99)

${ }^{68}$ Oponiéndose entonces a una justificación terapéutica de la pena que no reconoce en el autor del delito a un agente moral racional.

${ }^{69}$ MORRIS (1988), p. 69.

70 Ross (1975), pp. 37 y 38.

71 KINDHÄUSER (2009), pp. 93, 100 y 101.

72 Mañalich (2007), p. 187. Igualmente: Mañalich (2005), pp. 65 y ss. 
decir, una defraudación de la expectativa de fidelidad al derecho, la cual puede entonces ser legítimamente reprochada mediante la pena ${ }^{73}$. Así, la legitimidad del reproche penal no depende inmediatamente de las cualidades moralmente sustantivas del comportamiento, sino que de la legitimidad de la norma infringida, la cual a su vez está determinada por su forma de producción lega ${ }^{74}$; es decir, el fundamento del reproche se encuentra en la contradicción formal de una norma democráticamente generada ${ }^{75}$.

El problema que presenta una teoría de la pena retribucionista, expresiva de reproche, para una institución regulativa, es que el reproche exige honestidad para poder ser realizado de manera "feliz": siendo el reproche una reacción que exhibe emociones ante los hechos de otro, entonces para ser exitoso, para poder efectivamente reprochar, se debe actuar con sinceridad ${ }^{76}$, es decir, la reacción debe responder efectivamente a la emoción de "reprochar"77, y ello excluye la posibilidad de mantener una actitud objetivante respecto del destinatario ${ }^{78}$, por lo que la sinceridad es incompatible con realizar la expresión con la finalidad de alcanzar una meta, ya que el objeto del reproche es la acción ya realizada; mientras que la meta perseguida, por definición, se encuentra en el futuro. En esa medida, se afirma que la justificación retrospectiva de la pena tiene carácter excluyente ${ }^{79}$, por cuanto el reproche exige que quien lo realice entienda que la razón para éste "se agota en el hecho de que al destinatario del reproche resulta imputable el quebrantamiento de una norma" ${ }^{80}$; y ello parece exigir una aplicación propia de una institución "constitutiva", es decir, pre-moderna.

Así, la cualidad excluyente del reproche importa el rechazo de una teoría retributiva como la de von Hirsch. En esta última, se comparte la afirmación de que al castigar se está expresando un reproche ${ }^{81}$, el cual se justifica en un defecto material de la conducta realizada: sólo se puede reprochar un acto que en alguna manera sea reprensible ${ }^{82}$, lo que dependerá -si nos centramos sólo en el

\footnotetext{
73 Mañalich (2010), p. 53; Mañalich (2005), p. 63.

74 Mañalich (2010), p. 64.

75 Mañalich (2005), p. 68.

76 Sobre la sinceridad como condición de felicidad, véase: SEARLE (2007), p. 74.

77 MaÑALICH (2007), p. 159

78 Mañalich (2007), p. 156; Mañalich (2005), p. 70.

79 MaÑalich (2005), p. 74.

80 Mañalich (2010), p. 54.

81 VON HIRSCH (1998), p. 26.

82 Simester y Von Hirsch (2009), p. 90.
} 
harm principle ${ }^{83}$ - del daño que ha causado y de la culpabilidad del autor ${ }^{84}$. Pero al abordar la justificación del "sufrimiento penal", von Hirsch incluye consideraciones prevencionistas, que resultarán incompatibles con la expresión de un reproche. Ello tiene su origen en que la función expresiva de reproche pareciera no requerir necesariamente de la coacción y el maltrato que constituye la pena, planteándose que en principio se podría reprochar mediante vehículos distintos. Siendo ello así, se debe ofrecer una justificación de por qué para reprochar se recurre a un medio que genera tanto dolor como la pena. En los términos de Feinberg, se trata de justificar nuestros símbolos para expresar infamia ${ }^{85}$. Von Hirsch se refiere al punto indicando que "the reason for punishing (i.e., expressing disapproval through hard treatment) instead of merely censuring has to do with keeping predatory behavior within tolerable limits. Hard punishment no usefulness in preventing crime, then one would not need to visit material deprivation on those who offend" ${ }^{\prime \prime 6}$. Con ello se busca compatibilizar la satisfacción de necesidades preventivas con la necesidad -propia del retribucionismo- de reconocer al delincuente como agente moral, sosteniendo que aquellos que no se motiven sólo por la censura, verán en la amenaza de pena una razón de prudencia adicional para la abstención de la realización del tipo, lo que supone ver en el sujeto a un ser moral falible, pero no a una bestia controlable sólo por miedo ${ }^{87}$.

Anthony Duff también intenta conciliar la expresión de juicios de reproche con el logro de finalidades preventivas, $y$, al igual que von Hirsch, hace descansar la retribución en la cualidad sustantivamente reprochable de la conducta realizada, la cual debe constituir un mal público que requiera de una respuesta pública ${ }^{88}$. Ello lo lleva a sostener que el derecho penal se justifica por cuanto permite castigar conductas reprochables ${ }^{89}$. Pero junto con ello, Duff señala que el castigo debe buscar algo más y no ser solamente punitivo ${ }^{90}$. Así, el castigo retribu-

\footnotetext{
${ }^{83}$ Junto al cual se considera el paternalismo, que podría justificar el derecho penal en tanto que la medida paternalista aumente la autodeterminación de los afectados por ella (VON HIRSCH (1998), p. 52.); y la ofensividad, la cual se referiría la injusta producción de sentimientos indeseados (VON HIRSCH (2007), p. 50). Al respecto, véase igualmente HörNLE (2001); HÖRNLE (2007), pp. 383-399.

${ }^{84}$ VON HIRSCH (2009b), p. 143.

85 Feinberg (1974b), p. 116.

${ }^{86}$ VON HIRSCH (1992), p. 74.

${ }^{87}$ VON HIRSCH (2009a), pp. 117 y 118; igualmente en: VON HIRSCH (1998), p. 41.

${ }^{88}$ Duff (2003c), p. 47; Duff (2003b), p. 184.

${ }^{89}$ Duff (2002), pp. 97-108.

${ }_{90}$ Duff (2003b), p. 183. Una defensa de la propuesta de Duff (particularmente bajo su articulación en: Duff (2003a), pp. 295-312) puede encontrarse en VAlenzuelA (2010), pp. 255-268.
} 
ye mediante censura, lo cual sirve para reparar a la víctima y tiende a finalidades preventivo especiales. Así, y de manera similar a lo propuesto anteriormente por la teoría de defensa social ${ }^{91}$, Duff Ilama a que después de afirmada la condena, se abra un término de discusión que debe servir a múltiples objetivos: por un lado, se debe expresar censura y reproche al autor por su hecho cometido, lo que debe tender a buscar su arrepentimiento; pero igualmente se debe debatir acerca de la sanción concreta que, causando dolor al condenado, resulte idónea para reparar a la víctima y favorecer la resocialización ${ }^{92}$. En esto, Duff ve una teoría que, si bien mira al futuro, no es consecuencialista: la relación entre el castigo y sus efectos beneficiosos no es contingente, sino que la reconciliación y resocialización requieren de una disculpa mediante sufrimiento ${ }^{93}$.

El problema de una concepción del reproche que exige honestidad hacia la opción de von Hirsch se explica en que ésta negaría la posibilidad de estar reprochando si simultáneamente se está persiguiendo la finalidad de desincentivar el delito. Es la irrogación del mal -es decir, la ejecución de la condena-, y no la declaración de culpabilidad -es decir, el veredicto condenatorio-, lo que constituye el reproche ${ }^{94}$, y si ello es así, esa ejecución no puede perseguir la

91 De esta forma, se realiza una distinción entre dos momentos distintos dentro del juicio: primero está la etapa de conviction en que se analizan los hechos y la imputabilidad del autor; y posteriormente se llega al momento de sentencia, en que se discute cual es la sanción adecuada en consideración a las características personales del autor (véase: Beristaln (1961), p. 427); con lo que se comparte una diferenciación de von Liszt, quien si bien entrega la modalidad de la pena y sus cualidades a la política criminal basada en prevención especial, respeta la escuela clásica y la dogmática en un momento anterior: a la hora de determinar si hubo o no delito (en ese sentido, ZYSMAN (2012), p. 172).

92 Duff (2003c), p. 48; Duff (2003b), p. 188.

${ }^{93}$ Duff (2003c), p. 55. Jakobs también ha debido lidiar con la necesidad de conciliar los elementos simbólicos de la pena y su efectiva producción de dolor. Como parte del segundo estadio en la evolución de su teoría de la pena, se afirma que al consumarse el delito el autor no sólo ha significado algo, sino que también lo ha configurado, por lo que la reacción debe igualmente superar el puro plano del discurso, y en esa medida, es necesario privar al culpable de medios de interacción (es decir, reaccionar con violencia) para que efectivamente sea imposible formar un mundo común con él (JAKOBS (1998), pp. 24 y 25). En su segunda evolución, profundiza en el rol del dolor penal, indicando que éste debe servir para producir efectiva confianza entre los ciudadanos de que el derecho será respetado; es decir, el dolor penal no es sólo el vehículo por el cual se afirma la expectativa normativa eventualmente contrafáctica, sino que también busca directamente afirmar la expectativa cognitiva, por lo que su magnitud se relaciona con lo necesario para dar a entender que el proyecto delictivo del autor del delito ha fracasado. Se afirma entonces una relación estrecha entre distintas prevenciones: el dolor debe servir para generar confianza real entre ciudadanos, sirviendo a la prevención positiva referida a estados psicológicos; pero dicha confianza depende en parte de que el mismo dolor produzca un efecto de prevención general negativa suficiente (JAKOBS (2006)). Al respecto, sobre la evolución de la teoría de la pena en Jakobs, y en particular, sobre el rol de los efectos psicológicos a la hora de determinar la magnitud de la pena: SiLva (2006), p. 6.

94 MaÑalich (2007), pp. 161-163. 
finalidad de desincentivar la comisión de nuevos delitos. Igualmente, se opone a una opción como la de Duff, por cuanto no sería posible llevar adelante un debate con el infractor que busque reprocharle su conducta, y al mismo tiempo, estar pensando en qué medida concreta resulta más adecuado para reinsertarlo.

Esta misma objeción se puede formular al sofisticado intento de Robinson por compatibilizar las aproximaciones retributivas y utilitarias mediante su teoría de merecimiento empírico. La propuesta del autor estadounidense, de manera similar al esfuerzo previo, Rawls, afirma que un intento serio por alcanzar finalidades preventivas mediante el derecho penal exige justamente aplicar -por regla general- penas que obedezcan a criterios de merecimiento.

Para arribar a esa conclusión, el autor sostiene que del examen de estudios empíricos, es posible afirmar que un sistema de justicia criminal es más exitoso en términos de prevención de delitos, en la medida que aquel se corresponda con las intuiciones de justicia de los ciudadanos, adquiriendo por ese motivo "credibilidad moral" ante la comunidad. Así, Robinson plantea que, para que la ley goce de esa credibilidad, las sanciones establecidas deben responder a lo que denomina "merecimiento empírico". Éste se centra en la pregunta por el reproche que merece el autor de una acción, pero no en atención a un análisis de filosofía (de la) moral, sino que en consideración a estudios empíricos relativos a los factores que determinan las intuiciones de merecimiento de los miembros de la comunidad ${ }^{95}$.

Las ventajas preventivas de un derecho penal expresivo de merecimiento empírico se explican por varios motivos. En primer lugar, cuando el derecho penal es visto por la ciudadanía como coincidente con las normas sociales relativas a la corrección moral de comportamientos y sanciones, entonces hay mayor disposición a obedecer la ley, y su infracción por un sujeto conlleva una estigmatización por parte del resto de la comunidad que genera fuertes efectos preventivos $^{96}$.

Pero, más que el temor a la estigmatización, el derecho penal que se encuentra alineado con las intuiciones morales genera su mayor poder preventivo en la medida que influencia positivamente las fuerzas sociales e individuales de control conductual: el derecho penal desempeña un rol fundamental en crear y mantener el consenso social necesario para sostener normas morales que determinan la conducta de los agentes, trascendiendo las diferencias culturales y étnicas de las sociedades contemporáneas ${ }^{97}$. En esa medida, en tanto que se

95 Robinson (2008), p. 139. Igualmente, ROBINSON (2013), pp. 19-37.

96 Robinson (2008), pp. 175-178.

97 Robinson (2008), p. 186. 
refuerce la credibilidad moral de la ley, hay mayor obediencia a la misma por parte de la población, favoreciéndose el control de delitos.

Sobre la base de lo anterior, Robinson entiende que una regulación legal que sea coherente con los principios derivados de las intuiciones de justicia de la comunidad, no debería ser especialmente problemática ni para partidarios del utilitarismo ni del retribucionismo. Los primeros podrán ver que las sanciones aplicables serán efectivamente las que generará mayores efectos preventivos, mientras que los segundos verán que la pena a imponer será efectivamente determinada en consideración al merecimiento del autor ${ }^{98}$.

El problema que desde el retribucionismo expresivo se puede plantear a la opción de Robinson radica no sólo en que su teoría -precisamente por cuanto su fundamento se encuentra en la prevención de delitos- está disponible a alejarse de consideraciones de merecimiento en ciertos casos particulares en que ello sea particularmente conveniente ${ }^{99}$; sino que especialmente por cuanto conforme a ella la pena es incapaz de expresar felizmente un reproche por la conducta realizada. Robinson afirma que la principal objeción desde el retribucionismo obedecería a que el merecimiento empírico se aleja del merecimiento conforme a códigos morales de base filosófica ${ }^{100}$, pero el verdadero problema se deja explicar atendiendo a la razón por la cual el castigo se aplica: aquel tendrá lugar como parte de una estrategia de prevención de delitos, finalidad cuya persecución impide -como se indicó anteriormente- la formulación honesta de un reproche penal.

Así entonces, el dilema que se plantea es el siguiente: una teoría retributiva es incompatible con la persecución de finalidades mediante la imposición y ejecución de la pena, ya que con ello se frustraría la expresión misma del reproche; pero al mismo tiempo, una teoría de la pena debe enmarcarse dentro de un entendimiento del derecho como institución regulativa, conforme a la cual el derecho constituye instituciones jurídicas para lograr efectos que se valoran positivamente, los cuales nunca pueden dejarse completamente de lado en la aplicación del derecho, pero la consideración de esos efectos podría impedir la realización "feliz" del reproche.

\subsection{El restablecimiento por retribución}

La forma de salvar el problema es identificando adecuadamente lo que debe contar como finalidad de la práctica punitiva en general. Si a la retribución de

98 Robinson (2008), p. 210.

99 Robinson (2008), p. 248.

100 Robinson (2008), p. 210. 
culpabilidad por un déficit de fidelidad al derecho se le atribuyen finalidades preventivas de delitos, ya sean de prevención especial o general negativa, la práctica punitiva resulta autofrustrante: la persecución de esa finalidad impide formular el reproche retributivo. Pero esto se corrige acudiendo a la función restablecedora de la vigencia de la norma.

En la teoría hegeliana de la pena, el delito es visto como negación del ordenamiento que es a su vez negada por la pena, lo que permite a la realidad del Derecho "conciliarse consigo misma": la vulneración del Derecho existe positivamente sólo en cuanto voluntad individual del delincuente, voluntad que sería válida de no ser negada, pero cuya negación anula el delito restableciendo el Derecho.

Ello permite que la relación entre delito y pena no sea una sucesión irracional de males, sino que una superación del delito. Y es que el delito mismo no es visto como la producción de un mal, sino como vulneración del Derecho en tanto Derecho, y es entonces ese mal -la vulneración del Derecho- el que debe ser negado ${ }^{101}$. Con ello, el mal del delito se define no por su naturaleza específica externa; sino que por su valor, debiendo entonces haber una "igualdad interna" entre pena y delito, y no la igualdad del talión que mira las formas de existencia específica de las $\operatorname{cosas}^{102}$. Ello no debería entenderse, por supuesto, como negación de que la pena supone externamente una afectación perjudicial de derechos susceptible de ser caracterizada como "mal", sino que más bien importa que lo relevante no es inmediatamente el efecto que -utilizando nomenclatura jakobsiana- tiene lugar en la naturaleza, sino que el significado de ese evento respecto de la vigencia de la norma ${ }^{103}$. Y es justamente por constituir un mal que ese efecto en el mundo físico resulta apto para expresar reproche y con ello restablecer el Derecho infringido.

La legitimación de la retribución al delincuente, que se expresa en el $\$ 100$ de la "Filosofía del Derecho", es la misma que las actuales teorías retributivas esgrimen para legitimar el reproche penal: debe ser posible reconducir el castigo al mismo autor del delito, de forma tal que el Derecho que se le aplique sea su propio Derecho; y por ello Hegel señala que la pena constituye la aplicación al delincuente de su propia máxima universal expresada con su acción, por lo que al aplicársele su propio Derecho, se le está honrando como ser racio-

\footnotetext{
101 HeGel (2009), §97 a §99.

102 Hegel (2009), § 101.

103 JAKOBS (2000a), p. 153. El autor señala que el movimiento corporal, en tanto dato naturalista, es irrelevante para el derecho penal: sólo cuando es entendido como expresión de sentido de persona competente adquiere significado social; en: JAKOBS (1996), p. 71.
} 
nal ${ }^{104}$; argumento que es posteriormente reformulado en clave comunitaria por el retribucionismo contemporáneo, afirmando que la pena reconoce al autor como miembro de la comunidad política (o negativamente, que la pertenencia a ella es condición de la pena): al fundarse el reproche de culpabilidad en el entendimiento del infractor como autor de la norma, la pena supone el estatus de ciudadano del sancionado, por lo que su imposición es reconocimiento de este último como un igual al interior de la comunidad ${ }^{105}$.

De esta forma, es la retribución al delincuente conforme a su propia ley (la afectación de sus derechos, es decir, la imposición de un mal) lo que posibilita el efecto preventivo general positivo de restablecimiento de la vigencia como eficacia en tanto razón para la acción ${ }^{106}$ del Derecho en tanto Derecho.

Esta relación entre prevención general positiva y retribución es explícita en el mismo Welzel. Para su finalismo, la misión del derecho penal se encuentra en el amparo de los valores elementales de la vida en comunidad que constituyen el sustrato ético-social de la normas penales. En ese esquema, al apartarse de esos valores, resulta necesario exteriorizar la validez inviolable de los mismos mediante la sanción ${ }^{107}$, entendiendo que es precisamente la "retribución justa" la que permite afirmar el juicio ético-social que "establece la armonía de merecimiento de pena y pena, posibilitando finalmente al autor tolerar la pena como expiación justa por su hecho injusto". La dimensión estatal de esta retribución tiene lugar, no en tanto ella sirva a la realización de la justicia en sí, sino que en la medida que dicha sanción, al asegurar la vigencia de los valores sociales esenciales, sirve al mantenimiento del orden en la comunidad ${ }^{108}$.

Entre los autores tradicionales de la dogmática italiana, la idea de prevención mediante retribución puede ser vista en el expiacionismo iusnaturalista de Maggiore, quien entiende al delito como una acción que ofende gravemente el orden ético-jurídico (identificable mediante recta razón), y cuya retribución es necesaria para la reintegración ${ }^{109}$. Así, rechazando la idea de que el delito genere un derecho público subjetivo del Estado a castigar ${ }^{110}$, Maggiore sostiene que es la misma ley moral la que impone la necesidad de retribución, siendo el Estado

\footnotetext{
104 HeGel (2009), § 100.

105 MaÑalich (2005), p. 75.

106 Mañalich hace presente que en un sistema jurídico reflexivo, la vigencia como validez no se ve inmediatamente afectada por un incumplimiento (MAÑALICH (2010), pp. 50 y 53.

107 Welzel (1956), pp. 3-7.

108 Welzel (1956), pp. 234-237.

109 Maggiore (1986b), pp. 251 y 255.

110 Por cuanto ello supondría afirmar que Estado y delincuente se encuentran en una relación similar a acreedor y deudor (MAGGIORE (1986b), pp. 231-236.
} 
portador del derecho a retribuir. De esta forma, la pena, al retribuir y expiar, afirma el orden violado y se relaciona con el Derecho en tanto orden jurídico objetivo que es reintegrado ${ }^{111}$, confirmando la santidad de la ley y sirviendo a las necesidades supremas del orden ético ${ }^{112}$. Ello lleva a Maggiore a concluir afirmando que la pena es un mal conminado e infligido al reo, para reintegrar el orden jurídico, y como retribución del mal del delito ${ }^{113}$.

Con anterioridad a ambos autores, ya Merkel -no obstante ser un exponente de las teorías eclécticas ${ }^{114}$ - había sido particularmente claro en la relación de retribución y prevención general: el delito infringe una obligación jurídica original, generando con ello una nueva obligación que ocupa el lugar de la ya vulnerada, en virtud de la cual el culpable debe dejar recaer sobre él la consecuencia del delito, con lo cual se busca hacer valer los intereses reconocidos en la pretensión primaria, lo que mantiene la soberanía del derecho a pesar de haber sido infringido ${ }^{115}$. Ahora bien, al penar-es decir, al satisfacer la obligación secundaria subrogante de la obligación infringida-, lo que se está haciendo es emitir un juicio de reproche a la acción que violó el precepto primario, con lo cual se genera respeto y consideración hacia esa regla y hacia la voluntad que exige su obediencia ${ }^{116}$. Es decir, se generan efectos preventivo-generales positivos, mediante la retribución de culpabilidad.

En la actualidad, Mañalich -siguiendo a Binding-defiende una concepción similar: la forma de operación de ese restablecimiento consiste en que ante el incumplimiento insalvable de la obligación primaria de no realizar el tipo penal de la correspondiente norma de comportamiento, el derecho sustituye esa obligación por una secundaria, consistente en el deber tolerar la imposición de la pena, cuyo cumplimiento constituye el restablecimiento de la vigencia fáctica

111 MagGiore (1986a), p. 227, oponiéndose esa dimensión del Derecho a su dimensión de derecho subjetivo individual.

112 MAGgiore (1986a), pp. 223 y 256.

113 MagGiore (1986a), p. 263 En términos relativamente similares, Alf Ross indica que la retribución de la infracción es necesaria para el funcionamiento del sistema normativo, por cuanto la vigencia de la norma social supone que su vulneración sea sancionada (Ross (1975), p. 37). También desde el neokantismo se ha afirmado algo en la misma línea, intentando conciliar la idea de finalidad con retribución: para von Beling es el castigo el que sirve a la consecución de la finalidad de mantenimiento de la autoridad (VON BeLING (2002), p. 24.

114 Luego de su explicación de las relaciones entre prevención general y retribución, Merkel incluye finalidades preventivo-generales de intimidación en la amenaza penal, y agrega además consideraciones preventivo-especiales de corrección e imposibilitación dependiendo del tipo de autor (MERKEL (1910), pp. 258 a 267); por lo que su trabajo no puede sino considerarse como uno de los impulsores de las teorías mixtas o de la unión.

115 Merkel (1910), pp. 246 y 247.

116 Merkel (1910), pp. 251-253. 
de la norma primaria infringida ${ }^{117}$, con lo que se asocia el derecho coercitivo establecido en la norma de sanción con derecho principal correlativo al deber infringido de cumplir la norma primaria ${ }^{118}$.

Y bien vale la pena destacar justamente la naturaleza no imperativa de la norma secundaria respecto del juez. Así, cuando Mañalich afirma que la ocurrencia de un quebrantamiento imputable sólo opera como fuente de un derecho subjetivo del Estado a penar, pero no de un deber ${ }^{119}$, ello se condice con el entendimiento de la norma de sanción como una norma que confiere poder: ellas comprenden la potestad de dirigir la aplicación de penas por parte de funcionarios, y en esa medida, son "secundarias" -en la terminología hartiana- no por su posición en el sistema jurídico, sino que en atención a su función, la cual consiste en fijar institucionalmente las condiciones de autorealización del sistema ${ }^{120}$.

La estructura de estas normas, y el tipo de reglas que ellas entrañan, puede advertirse siguiendo en esto el trabajo de MacCormick. Así, es posible distinguir en un sistema jurídico reglas (1) "institutivas" que, en línea con las reglas constitutivas de Searle, sirven para atribuir a ciertos hechos la cualidad de instanciar una institución; de forma tal que, dada la verificación de esos hechos, pasan a tener aplicación ciertas reglas (2) "consecuenciales" que disponen la aplicación de consecuencias en caso de concretarse una instancia particular de la institución creada por la regla institutiva ${ }^{121}$.

Luego, las normas de derecho penal pueden comprenderse como un sistema de diversas reglas constitutivas y regulativas relacionadas. La norma de conducta "prohibido $\Phi$ " corresponde entonces a la regla institutiva/constitutiva que asigna a cierto comportamiento el estatus funcional de "prohibido". Ahora bien, dicho estatus institucional asignado a $\Phi$ acarrea un poder deóntico negativo conforme al cual "no debe realizarse $\Phi$ ", lo que constituye una razón independiente para la acción ${ }^{122}$, por lo que es correcto afirmar que la norma "es establecida por un acto que pretende ser tomado por los sujetos normativos como una razón excluyente para la acción"123. Esto quiere decir que si bien la norma configura

\footnotetext{
117 Mañalich (2010), p. 60.

118 Mañalich (2010), p. 59.

119 Mañalich (2010), p. 63.

120 Mañalich (2012), pp. 580 y ss.

121 MacCormick y Weinberger (1992), pp. 51 y ss.; MacCormick y Weinberger (1986), pp. 131 y ss. A estos dos tipos de reglas se suman las reglas "terminativas", que establecen las condiciones para que deje de existir la instancia creada de la institución.

122 SeArle (2010), p. 167.

123 RAZ (1991), p. 93.
} 
el mundo de una determinada forma, es la existencia de la norma y no la norma misma lo que constituye una razón para la acción ${ }^{124}$. De esta forma, la norma de conducta posee características tanto de actos declarativos como directivos ${ }^{125}$ : se puede entender que su finalidad consiste en lograr que el oyente se abstenga de realizar $\Phi^{126}$, que esta meta se alcanza haciendo que esté prohibido $\Phi$, y que esa configuración del mundo tiene lugar declarando "prohibido $\Phi^{\prime \prime 127}$.

Ahora bien, la defensa de la autonomía de las normas de comportamiento respecto de las normas de sanción (es decir, entender que la existencia de una obligación no requiere de la inclusión de una sanción aparejada a su quebrantamiento imputable), debería llevar a negar que dicha norma de conducta entrañara a su vez una regla consecuencial que disponga que "de verificarse una instancia del hecho institucional 'prohibido', el Juez penal está facultado para castigar a quien se le impute dicho quebrantamiento". Sólo en un entendimiento del derecho como fundamentalmente coercitivo dicho entrañamiento es indispensable para afirmar que el sistema jurídico ordena una omisión. Así, si siguiéramos a Kelsen -y entendiéramos por ello que la naturaleza coercitiva del derecho se encuentra en que las normas de éste prescriben actos coercitivos constitutivos de sanciones como consecuencia de la realización de ciertas conductas-, entonces resultaría que la conducta ordenada sólo se podría identificar con la inversión de la conducta a la que la sanción se impone ${ }^{128}$. Si ello fuera así, entonces la promulgación de una pura norma de conducta sin sanción aparejada, resultaría en que el enunciado en cuestión no podría ser entendido como una norma jurídica, debiendo ser considerada como legamente irrelevante ${ }^{129}$.

Por el contrario, en oposición a una visión imperativista en que la norma de conducta es "dependiente", si entendemos que para encontrarnos ante normas completas basta con la declaración del puro estatus de prohibido y la derivada fuerza directiva en tanto razón excluyente para la omisión, entonces la cualidad sancionable de la conducta $\Phi$ no se sigue sólo de la veracidad de la proposición normativa "existe una norma que prohíbe $\Phi$ "; sino que la posibilidad de sancionar sólo tiene lugar recién con la emisión de la norma de sanción.

\footnotetext{
${ }^{124}$ RAZ (1991), p. 57: La norma es un objeto, y por tanto, la razón para la acción es el hecho de que dicho objeto existe.

125 Mañalich (2012), pp. 583 y ss.

126 Searle (1976), p. 11.

127 Searle (1976), p. 13 y ss.

128 KelSen (2005), pp. 34 y 35.

129 KeLSEN (2005), p. 52. Igualmente irrelevante resulta en esta concepción toda ley que adopte la forma de una declaración de la cual un acto directivo no puede extraerse.
} 
Respecto de esta última, hemos dicho que si las normas de sanción no poseen naturaleza imperativa respecto del juez ${ }^{130}$, entonces la configuración de este modelo requiere extraer de dicha norma secundaria reglas que otorguen al juez potestad tanto para (1) "determinar, en forma revestida de autoridad, si en una ocasión particular se ha transgredido una norma primaria"; como para (2) "disponer la aplicación de penas por otros funcionarios"131. Ahora bien, habiendo una relación entre reglas institutivas/constitutivas y reglas que confieren poderes ${ }^{132}$, parece lógico afirmar que la primera potestad indicada se encuentra configurada por una regla institutiva/constitutiva conforme a la cual (1) "lo que el Juez penal determine cuenta como quebrantamiento imputable de la norma de conducta".

La segunda potestad, por su parte, también podría presentarse recurriendo a una pareja de reglas de ese tipo, según las cuales (2.1.a) "el quebrantamiento imputable de una norma de conducta cuenta como sancionable" y (2.2.a) "la reacción de juez ante el quebrantamiento imputable cuenta como sanción"133; pero, en atención a que no toda regla que confiere poder es necesariamente una regla institutiva/constitutiva ${ }^{134}$, creo que la potestad punitiva del Juez se deja articular de mejor manera combinando un regla institutiva/constitutiva con otra consecuencial: (2.1.b) "el quebrantamiento imputable de una norma de conducta cuenta como sancionable"; (2.2.b) "de verificarse una instancia del hecho institucional 'sancionable', el Juez penal está facultado para sancionar a quien le impute dicho quebrantamiento". Luego, en la medida que la consecuencia normativa que tiene lugar por la verificación del hecho operativo consiste en que el Tribunal se encuentra facultado para imponer la sanción correspondiente, es posible comprender a dicha regla consecuencial como una que confiere poder al juez penal.

Ahora bien, para apreciar adecuadamente la forma en que opera esta potestad sancionatoria, es necesario precisar que lo que se ha concedido al Juez es poder normativo, el cual, a su vez, se puede caracterizar como la posibilidad de realizar un cambio en los derechos o deberes del sujeto a quien se le imputa la conducta prohibida, realizándose un cambio normativo mediante un acto

130 Sobre la reacción ocasionada por la hipotética inobservancia por parte de la autoridad de reglas secundarias, y su distinción de la coacción que tiene lugar por la infracción de una regla primaria, véase el interesante trabajo de Molina (2011).

131 HART (1998), pp. 120 y 121.

132 MacCormick y WeinberGer (1992), pp. 59-62.

133 Si lo entiendo correctamente, de esta forma podrían expresarse las reglas constitutivas a que hace referencia MAÑALICH (2012), p. 582.

134 MacCormick y Weinberger (1992), pp. 63 y ss. 
del habla consistente en la dictación de una nueva norma de mandato ${ }^{135}$ que ordena castigar a dicho agente. Esta configuración concreta del poder normativo del Juez requiere relacionar dicha regla consecuencial, derivada de la norma de sanción, con una regla institutiva/constitutiva establecida -en el caso chilenopor el artículo 76, inciso $3^{\circ}$ del D.L. № 3.464, conforme al cual "la condena dictada por parte del Tribunal constituye una norma de mandato que debe ser obedecida por funcionarios correspondientes".

Lo relevante de todo esto es que, en tanto que la ejecución de la pena corresponde a la aplicación de reglas institutivas/constitutivas de una institución regulativa, dicha práctica debe realizarse de forma tal que ella sirva a la finalidad perseguida con el establecimiento de dichas reglas. La particularidad distintiva de la practica punitiva se encuentra en que la finalidad de la misma, en la medida que consista en restablecer la vigencia de la norma de conducta, no es posible de ser alcanzada si aquella se persigue de manera directa: sólo en la medida que la pena se aplique retributivamente para el único efecto de reprochar culpabilidad, ésta podrá restablecer la vigencia fáctica de la norma de conducta infringida. Dicho con otras palabras, el restablecimiento de la norma primaria de conducta es el objetivo que fundamenta la norma secundaria de sanción, cuyo seguimiento consiste en una práctica retributiva que supone ignorar dicho fundamento.

Volviendo a Merkel, es el juicio de reproche a la acción que violó el precepto primario lo que produce su restablecimiento ${ }^{136}$, y si el reproche requiere honestidad, entonces no se puede aplicar la pena para lograr el restablecimiento, sino que sólo para reprochar ${ }^{137}$. Es decir, aun cuando el restablecimiento no es un fin ulterior del reproche, sino que el reproche es el restablecimiento, por lo que ambos ocurren simultáneamente ${ }^{138}$, de todas formas es posible distinguirlos

135 RAZ (1991), pp. 113 y ss.

136 MeRKel (1910), pp. 251-253.

137 De esta forma, si se entendiera que ambas reglas extraídas a partir de la norma de sanción se encuentran integradas por el indicado defeater que condiciona su aplicación a casos normales, ello supondría que la evaluación acerca de la normalidad del caso concreto no sólo no puede dar paso a que se tomen en cuenta factores relevantes a efectos preventivos, sino que en general obliga a excluir la consideración de cualquier antecedente cuya evaluación suponga otorgar un trato objetivante al condenado, incluyéndose el análisis acerca de la necesidad de restablecer la vigencia de la norma infringida. Si no resultara posible identificar un factor que se pudiera considerar para la evaluación de la normalidad del caso concreto, sin que ello implicara tratar de manera objetivante al condenado, igualmente la norma de sanción podría ser entendida como derrotable: siguiendo a Hage, para que una regla sea derrotable no es necesario que exista de hecho una excepción en un caso particular, sino que basta con que sea teóricamente posible que exista un caso en el cual, cumpliéndose sus hechos operativos explícitos, igualmente deba hacerse una excepción en atención al defeater implícito (HaGE (2003), pp. 232 y 233).

138 MaÑalich (2010), p. 65. 
conceptualmente, y con ello se abre la puerta -en principio- para una práctica auto-frustrante: si la pena se aplicara en el caso concreto porque con ella se restablece la vigencia de la norma, si bien no habrá una disociación entre derecho coercitivo y derecho principal, sí habría un trato objetivante hacia el condenado que impedirá la formulación de un reproche honesto, y ello conIlevaría el fracaso del restablecimiento de la norma.

Esto se puede expresar más claramente recurriendo a la estructura que Searle propone relativa al razonamiento práctico. Para ello, en primer lugar, se deben distinguir los silogismos en los que la conclusión del razonamiento está constituida por algo que es deseado por sí mismo, de aquellos en los que lo deseado se desea sólo como medio para otra cosa. En segundo lugar, junto con esa distinción es necesario además identificar tres nociones que sirven para constituir las premisas del razonamiento: los "motivators", que corresponden típicamente a deseos u obligaciones, constituyen razones para la acción de dirección mundo a mente, en tanto que buscan cambiar la realidad para que ésta se adecúe al estado intencional; los "effectors", por su parte, corresponden a medios que causan el fin deseado; y finalmente, los "constitutors", que no causan la configuración del fin deseado, sino que constituyen ese fin ${ }^{139}$.

Ahora bien, en tanto que los "constitutors" pueden formar parte de ambos tipos de razonamientos prácticos, entonces no basta, para excluir la posibilidad de otorgar un trato objetivante, con afirmar que el reproche no causa el restablecimiento, sino que lo constituye: supongamos que la emisión de una oración en inglés constituyera prueba de que el emisor de la oración habla ese idioma. Si yo, deseando probar que hablo inglés, emito la expresión "I speak english", entonces, aun cuando la expresión indicada no causa el efecto de que yo haya hablado inglés, sino que opera como "constitutor" respecto del fin "hablar inglés", y a su vez, "hablar inglés" constituye la prueba de que se habla inglés; igualmente emitir una oración en inglés no era algo que yo deseaba por sí mismo, sino que lo deseaba en tanto constituía otra cosa (prueba de que hablo inglés), la cual -esa sí- era deseada por sí misma.

Así, y respecto de la acción "penar", se podría razonar que ella es "constitutor" de reprochar, lo cual a su vez es "constitutor" del restablecimiento de la norma, restablecimiento que configura el "motivator" del razonamiento. Si ese fuera el caso, aun cuando el reproche deseado no opera como "effector", igualmente la acción de reprochar no es deseada por sí misma, sino que como medio. Si lo anterior es correcto, entonces la exclusión del trato objetivante requiere no sólo que el reproche sea "constitutor" del restablecimiento, sino también que el "motivator" sea el reproche mismo.

139 Searle (2010), pp. 125-127. 
Luego, si la justificación de la práctica en general es lograr el restablecimiento de normas, y si por tratarse de una institución regulativa esa justificación no debe desatenderse a la hora de su aplicación a casos concretos, entonces la estructura regulativa de la institución exige su aplicación como si se tratara de una institución constitutiva. Así, el esquema de Mabbott, cristalizado en el trabajo de Rawls, es correcto: la justificación general de la práctica punitiva no puede ser tomada en consideración al momento de su aplicación. Pero la razón de esto no se encuentra en que el derecho sea una institución constitutiva, o en que la práctica punitiva esté configurada por "reglas como prácticas"; sino que se explica en atención a que la justificación general de la norma de sanción solo puede ser alcanzada en los casos concretos si ella se aplica sin perseguir intencionadamente esa justificación.

Todo lo anterior tiene como corolario que, desde la perspectiva de la aplicación concreta de la pena a un caso determinado, el efecto restablecedor sólo puede ser visto como un efecto que tiene lugar por añadidura.

\section{Sobre la distancia entre teoría y práctica: la pena existente como significando imperfectamente}

Ante una concepción retributiva de la pena se han alzado varias críticas desde las posiciones prevencionistas, entre ellas, que una pena retributiva constituye una introducción de elementos moralizantes en el derecho, careciendo el Estado de potestad para perseguir la justicia; o que una pena que no persigue la producción de efectos positivos resulta irracional, y por lo tanto, ilegítima en un Estado de derecho ${ }^{140}$. Objeciones como éstas han recibido respuestas sólidas desde el retribucionismo ${ }^{141}$. En esta última parte, se intentará dar cuenta de un problema diverso al cual la opción acá defendida debe referirse: la efectiva inexistencia de un derecho penal retributivo y el fracaso de los presupuestos del mismo.

La regulación española sobre el servicio de prisiones establece expresamente que la resocialización del condenado constituye la finalidad primordial de la ejecución de las penas. De forma relativamente similar, el $\S 46, N^{\circ} 1$ del StGB dispone que en la fijación de pena se deben considerar las consecuencias esperables que la pena genere en la vida futura del condenado. La regulación chilena igualmente ordena al juez tomar en consideración la finalidad de resocializar al condenado a efectos de determinar la pena concreta a aplicar, en particular, indicando -por ejemplo- que la pena de libertad vigilada intensiva sólo puede

140 A modo de ejemplo: MiR (2006), pp. 38 y ss.; SiLva (2010), pp. 5 y ss., 322 y ss.; Roxin (1997), p. 84.

141 Véase en general el trabajo ya citado de Mañalich (2007). 
tener lugar si aquella parece eficaz para la reinserción social del delincuente. Como bien hace presente Mir, todas estas consideraciones impiden afirmar que en el derecho penal vigente se siga una concepción retributiva de la pena: "Es absolutamente opuesto a la función retributiva de la pena el contenido que le asigna expresamente la normativa vigente en materia de ejecución de las penas privativas de libertad"; concluyendo que la prevención especial es incompatible con el principio de justicia ${ }^{142}$.

Ello significa que desde una visión retribucionista se debe negar que aquello que normalmente denominamos "pena", sean efectivamente una pena. Más aún, la disonancia cognitiva es mayor de lo que en principio aparenta: no sólo nuestro derecho penal es incompatible con un entendimiento retributivo de la pena, sino que los presupuestos de legitimidad de la retribución están ausentes de nuestras prácticas políticas. Esta idea de fondo es intuida, pero mal identificada, por quienes rechazan una pena retributiva aduciendo que no se puede probar el libre albedrío, el cual fundamentaría la expresión de reproche ${ }^{143}$. Ello se puede salvar mediante el recurso al compatibilismo, en el cual el poder actuar de modo diverso es entendido como dependiente de que el sujeto hubiera "decidido actuar de modo diverso"144. El problema, entonces, no se encuentra en la libertad como presupuesto, sino que en las precondiciones de organización social que se requieren cumplir para que la pregunta por la responsabilidad penal pueda siquiera ser formulada.

En lo que sigue se intentará plantear que el contenido y carácter de esta proposición son correctos, pero que su destinatario es errado: efectivamente nuestras formas de vida no satisfacen las condiciones que posibilitan dirigir un reproche penal, y ello acertadamente sirve para dirigir una objeción, pero no contra la teoría retributiva de la pena, sino que contra nuestras formas de vida realmente existentes. La idea subyacente que sirve para explicar esto sólo podrá ser presentada en sus líneas generales, las cuales pueden sintetizarse indicando que la normatividad del Derecho descansa en un "compromiso irónico"145, por cuanto el Derecho fundamenta su normatividad en presupuestos que suponen su propia negación; por lo que éste, en tanto institución realmente existente, no está a la altura de sus "estándares inmanentes"146.

\footnotetext{
142 MIR (2003), pp. 84 y ss.

143 Al respecto, véase Roxin (1997), p. 84; StRATENWERTh (2005), p. 25. En la literatura española, entre otros: BaCigalupo (1996), p. 13 (al indicar que la retribución carece de fundamento empírico).

144 MaÑALICH (2007), pp. 144 y ss.

145 Esta idea ha sido desarrollada por AtRIA (2009), p. 34.

146 Mañalich (2013), p. 186.
} 


\subsection{La (inexistente) comunidad de intereses como fundamento y superación del Derecho}

Hemos dicho que la legitimidad del reproche depende de la posibilidad de reconducir la norma al sujeto que la ha quebrantado, quien debe ser visto como uno de los partícipes de un proceso de comunicación en que todos los involucrados, en igualdad de condiciones y reconociéndose recíprocamente capaces, definen los límites de las interacciones individuales. Pues bien, efectivamente esas condiciones ideales de interacción, referidas tanto a nuestros procesos formales de participación política como a nuestras formas de organizar la vida en comunidad, no existen en el mundo real. Como hace ver Mir, el hombre no es libre de las condiciones que le toca vivir ${ }^{147}$, y las instituciones sociales que sirven de mediación en los procesos de interacción social conducentes al entendimiento son parciales a favor de los intereses de ciertos grupos sociales por sobre otros. En palabras de Duff, la comunidad de valores y las estructuras políticas y económicas que el derecho protege no son compartidas por todos los ciudadanos: la desigualdad en las formas de vida que sirven de telón de fondo a los participantes de la comunicación importa una falta de lenguaje común que impide llamar a responder al otro por sus acciones ante el resto de la comunidad ${ }^{148}$. La observación de Duff, entonces, apunta a que bajo la realidad existente no se satisfacen los principios morales que justifican un derecho penal retributivo.

Para analizar el problema, partamos haciendo una breve referencia a Honoré, para quien la relación entre derecho y moral no puede ser entendida limitándose el primero a fortalecer o erosionar reglas de la segunda, sino que en ciertos casos el derecho mismo determina lo que la moralidad exige, de forma tal que no es posible identificar qué comportamiento es moralmente aceptable, sin haber atendido previamente al derecho. Ello se explicaría por cuanto la pregunta moral por la corrección o incorrección de una institución sólo es operativa si logra guiar el comportamiento en la vida real, pero en esa medida, la moral resulta inevitablemente incompleta: en tanto que esos juicios de corrección no pueden sino basarse en principios generales, los mismos - dada su generalidadson ineficaces para indicar una forma de comportamiento correcto en cada caso concreto ${ }^{149}$. Por el contrario, y a diferencia de la moral, el derecho debe guiar conductas concretas bajo las condiciones de vida realmente existentes. Ello significa que éste no puede reproducir principios de justicia ideales, pero

\footnotetext{
147 MIR (2006), p. 39.

148 Duff (1998), pp. 202 y 203.

149 Honoré (1993), p. 4. Esta idea se encuentra también en: HAYEK (1980), p. 39.
} 